\title{
A PRODUÇÃO CIENTÍFICA EM BORN GLOBALS NOS PERIÓDICOS E ENCONTROS CIENTÍFICOS BRASILEIROS
}

\author{
Thiago Alberto Viana de Sousa ${ }^{\Omega}$, Thomaz Novais Rocha ${ }^{1}$, Sérgio Henrique Arruda Cavalcante Forte \\ Universidade de Fortaleza - UNIFOR, Fortaleza, CE, (Brasil) \\ ${ }^{\Omega}$ Fundação Getúlio Vargas - FGV, São Paulo, SP, (Brasil)
}

\section{DETALHES DO ARTIGO}

Histórico do Artigo:

Recebido: 13 de fevereiro de 2019

Aceito: 15 de novembro de 2019

Disponível online: 01 de maio de 2020

Sistema de revisão "Double blind review"

Editor Científico

Ilan Avrichir

Palavras-chaves:

Born global

Internacionalização

Empresas internacionais

Estudo bibliométrico

\section{RESUMO}

\begin{abstract}
Objetivo: O objetivo deste artigo foi analisar a produção científica em periódicos brasileiros no tema born globals.

Método: Foi realizada uma análise bibliométrica de toda a produção científica no Brasil até o mês de outubro de 2019, nos periódicos de Qualis A1 a B3 e anais do ENANPAD.

Principais resultados: Dentro da temática abordada nos artigos, verifica-se uma predominância pelo processo de internacionalização das born globals e pela evolução do conceito de internacionalização. As instituições do sul e sudeste do Brasil são as que contabilizam maior número de publicações na temática.

Relevância/originalidade: Analisar a produção científica brasileira sobre born globals é útil para pesquisadores em seus futuros estudos sobre internacionalização.

Contribuições teóricas/metodológicas: A investigação contribui com a evolução teórica do tema, mostrando o desenvolvimento da pesquisa em born globals no Brasil ao longo dos anos.
\end{abstract}

\section{INTRODUÇÃO}

Nos estudos de internacionalização, um dos modelos mais utilizados para explicar a inserção de empresas em mercados externos é o Modelo de Uppsala, desenvolvido por Johanson e Vahlne (1977). Nele, a internacionalização é descrita como um processo gradual e lento, em que as empresas acumulam conhecimentos e recursos para reduzir incertezas e perdas ao se internacionalizarem.

No entanto, as últimas décadas trouxeram mudanças substanciais na abertura econômica dos países, somadas ao avanço do desenvolvimento tecnológico nos meios de comunicação e transporte, os quais facilitaram a internacionalização de empresas domésticas, além de permitir o surgimento de empresas born globals (BG), que já começam suas operações no exterior logo após o seu nascimento ou nos primeiros anos após a abertura (Dib, 2008; Knight \& Cavusgil, 1996; Rennie, 1993).

Oviatt e McDougall (1994) definem as BG como empresas que desde sua concepção, procuram tirar vantagem competitiva dos recursos e das vendas em vários países. O processo de internacionalização das BG é marcado por um engajamento rápido em mercados externos, quando as empresas podem operar em nichos ou mercados emergentes abertos a novas tecnologias (Chetty \& Campbell-Hunt, 2004).

Para Dzikowski (2018), é crescente o reconhecimento desse tipo de empresas como importantes organizações no cenário econômico internacional. Dentro desse contexto, Ribeiro e Pimentel (2009) destacam que o avanço das BG possui influência direta no desenvolvimento dos países, uma vez que estimula a internacionalização das empresas em busca de ambientes competitivos, clusters tecnológicos e redes empresariais de negócios. Em nível nacional, as BG podem trazer tendências e potencializar a participação do Brasil nas redes mundiais de desenvolvimento e conhecimento (Fleury \& Fleury, 2007).

No âmbito acadêmico, dentre os estudos sobre internacionalização de empresas, o surgimento das BG's tem obtido destaque em pesquisas, uma vez que essas empresas evidenciam uma condição inovadora

\footnotetext{
${ }^{1}$ Contato do autor - E-mail: thomaznr@gmail.com
} 
de internacionalização possibilitada por diversos elementos, como as redes de relacionamento, empreendedorismo e inovação organizacional (Lima \& Souza, 2016). Verdu e Bulgacov (2012) mostram que, a partir dos anos 2000, as pesquisas sobre negócios internacionais se intensificaram no Brasil, muito por conta da abertura do país para o mercado internacional na década de 90.

Nesse contexto, é apresentada a seguinte questão de pesquisa: como se encontra o desenvolvimento da pesquisa em born globals nos periódicos brasileiros? A partir deste questionamento, o objetivo do artigo é investigar a produção científica em born globals nos periódicos brasileiros e no ENANPAD.

Como suporte metodológico, foram considerados aspectos de cunho descritivo-quantitativo na busca e análise dos achados, bem como um levantamento bibliométrico frente aos periódicos nacionais na área de Administração de Qualis Capes A1 a B2.

Os estudos de internacionalização ainda são relativamente recentes na academia, principalmente com relação às BG, que surgiram apenas nos anos 90 . Em termos de relevância da pesquisa, a investigação busca contribuir com a evolução teórica do tema. Analisar a produção científica brasileira sobre BG pode ser útil para pesquisadores em seus futuros estudos sobre internacionalização.

\section{REFERENCIAL TEÓRICO}

\subsection{Empresas born globals}

Até o início dos anos 90, os estudos de empresas internacionais eram baseados em grandes corporações de países desenvolvidos, com enfoque nas teorias econômicas e comportamentais. $\mathrm{Na}$ abordagem econômica, destacam-se os estudos de Dunning (1988), que enfatizaram o movimento de internacionalização de grandes firmas na busca de escala, recursos naturais, eficiência de atividades ou ativos estratégicos, deixando de fora elementos que podem representar sucesso em mercados internacionais, como as cooperações e alianças estratégicas. Na abordagem comportamental, destaca-se o Modelo de Uppsala, de Johanson e Vahlne (1977), que apresenta a internacionalização como um processo lento e gradual de aprendizado. A empresa aumenta o seu comprometimento com mercados internacionais por etapas, em uma série de estágios evolutivos, o que é contrário a evidências empíricas de empresas que já surgem atuando em mercados internacionais (Madsen \& Servais, 1997).

Nesse contexto, nenhuma das abordagens tradicionais consegue explicar de maneira exata as empresas BG. A denominação BG surgiu pela primeira vez em 1993 durante um estudo feito ao Conselho de Manufatura Australiano (originalmente, "The Australian Manufacturing Council") pela consultoria Mckinsey \& Company (Rennie, 1993), que obteve um representativo número de empresas de vários setores industriais efetuando transações internacionais logo no início das suas atividades.

Vários são os fatores que explicam o aparecimento e o desenvolvimento dessas empresas. As diversas inovações tecnológicas, particularmente nas áreas de comunicação e transporte, geraram grandes reduções nos custos de transações para as empresas internacionalizadas no mundo globalizado. Além disso, o aumento da especialização dos mercados, levando ao surgimento de nichos também foi um ponto importante, pois trouxe espaços que podem ser explorados por empresas de menor porte (Madsen \& Servais, 1997; Oviatt \& Mcdougall, 1994).

Nas pesquisas, os diferentes nomes desse tipo de empresas mostram as variações desse fenômeno, como mostram Rialp, Rialp e Knight (2005). Termos como international new ventures (Oviatt \& Mcdougall, 1994), born globals (Knight \& Cavusgil, 1996) e global startups (Madsen \& Servais, 1997) mostram a heterogeneidade dos conceitos. Uma observação é que as teorias tradicionais de internacionalização não são capazes de explicar a ocorrência das born globals (Rialp et. al, 2005).

É importante notar que variados critérios têm sido empregados para traçar as características definidoras das BG (Dzikowzki, 2018). Nesse contexto, as pesquisas apontam diversas variáveis, como o tempo decorrido entre a fundação da empresa e a sua primeira exportação (Jones \& Coviello, 2005), o nível de velocidade do crescimento e do desenvolvimento internacional da empresa (Oviatt \& McDougall, 2005), além de fatores como data de fundação, abrangência dos mercados e porcentagem do faturamento resultante do desempenho da empresa no exterior (Dib, Da Rocha, \& Da Silva, 2010). Dentre as diversas proposições no tema, uma definição mais aceita é a de Knight e Cavusgil (2004), que aponta que as BG possuem, nos seus três primeiros anos, pelo menos $25 \%$ dos retornos vindos de vendas internacionais. 
Com relação ao desempenho desse tipo de empresa (BG), Oviatt e McDougall (1994) apresentaram algumas características que contribuem para o sucesso delas. São algumas delas: a visão global desde a concepção da empresa; gerentes com vivência internacional; redes internacionais fortes; superação de desvantagens por ter um produto ou serviço valioso; e contínua inovação para que a empresa continue evoluindo e explorando o nicho de mercado. Essas características corroboram com os estudos de Knight e Cavusgil (2004), que mostram que a performance das BG é diretamente relacionada com quatro aspectos: produtos únicos, capacidade tecnológica em nível global, foco em qualidade e alavancagem de competências do distribuidor internacional. Nesse contexto, Hennart (2014) relaciona a competência das BG à rapidez em adaptar produtos segmentados com necessidades específicas.

As BG, em sua maior parte, baseiam o seu modo de funcionamento nas novas tecnologias de informação, principalmente a internet, se estruturando de formas alternativas, com foco em recursos baseados em conhecimento e inovação nas suas operações (Knight \& Cavusgil, 2004; Ribeiro \& Pimentel, 2009). Dessa forma, entende-se que o processo de inovação é de grande relevância para a operação e sucesso das BG, uma vez que a capacidade de inovação é uma vantagem competitiva, se configurando como uma dinâmica que permite às empresas alcançarem um alto nível de competitividade em mercados internos e externos (Çakar \& Erturk, 2010).

Knight e Cavusgil (2015) também analisam os determinantes de desenvolvimento das BG, mostrando que estas empresas irão continuar crescendo à medida em que mantiverem foco em alguns aspectos principais: (a) manutenção de uma orientação empreendedora que busca inovação; (b) engajamento com as redes de clientes, fornecedores e parceiros; (c) habilidade de crescer e se tornar uma empresa mais complexa, porém sem perder a visão empreendedora; (d) continuar desenvolvendo as aptidões para balancear riscos e oportunidades. Essas características convergem com os estudos de Stocker e Abib (2019), que apontam que as BG possuem maior propensão a riscos do que empresas tradicionais. Gabrielsson, Kirpalani, Dimitratos, Solberg e Zucchella (2008) propõem que as BG se desenvolvem em três fases distintas. $\mathrm{Na}$ fase introdutória, em que a empresa tem recursos limitados e uma estrutura organizacional ainda pouco desenvolvida, a sua força principal vem da criatividade e das habilidades empreendedoras dos seus fundadores. Na segunda fase, chamada de crescimento e acumulação de recursos, a empresa aprende com os seus parceiros, com os membros das redes em que ela participa e com os próprios clientes iniciais. Hagen e Zuchella (2014) mostram que o crescimento das empresas BG está fortemente conectado às redes de contatos dos empreendedores, sejam essas redes pessoais ou profissionais. A terceira e última fase é o break-out, em que a empresa, a partir das experiências e aprendizagem organizacional, irá definir uma estratégia de crescimento global independente (Gabrielsson et al., 2008).

A variedade de perspectivas e conceitos utilizados nos estudos, bem como a inconsistência nas definições e os muitos critérios adotados tornou a pesquisa em BG muito heterogênea e inconclusiva (Keupp \& Gaussman, 2009). Apesar disso, a pesquisa em BG tem crescido, principalmente por conta das condições dos mercados e dos avanços na tecnologia (Chetty \& Campbell-Hunt, 2004). Dessa forma, Dzikowski (2018) apresentou um estudo bibliométrico, trazendo uma melhor definição de como se deu a evolução do estudo das born globals ao redor do mundo, dos anos de 1994 a 2016, tendo predominância dos Estados Unidos, Nova Zelândia, Austrália como países que mais influenciaram as pesquisas no tema. Ressalta-se que este estudo de 2018 é o primeiro artigo bibliométrico tratando especificamente sobre BG. Ainda tratando da pesquisa em BG, Madsen e Servais (1997) sugerem que uma integração entre a pesquisa em empreendedorismo e internacionalização, com foco nas características ambientais, organizacionais e dos empreendedores pode trazer um maior desenvolvimento para o fenômeno das BG.

\subsection{As leis da bibliometria}

O termo foi originalmente proposto por Pritchard na década de 1960 (Chueke \& Amatucci, 2015). Kobashi e Santos (2008, p. 109) relatam que "a bibliometria é uma metodologia que faz um levantamento das atividades científicas e correlatas, sendo possível por meio de uma análise dos dados que mostrem as mesmas características".

Ferreira (2010) explica ainda que a bibliometria é a utilização de método quantitativo e estatístico de medição dos índices de produção e disseminação do 
conhecimento científico. Por meio dessa metodologia, pode-se, por exemplo, "distinguir o número de trabalhos sobre um determinado assunto; publicados precisamente em uma data; publicados por um autor ou por uma instituição" (Kobashi \& Santos, 2008, p. 109).

Oliveira e Sales (2014) afirmam que os estudos bibliométricos, além de serem objeto de estudos da Biblioteconomia e da Ciência da Informação, são utilizados como método de pesquisa em diversas áreas do conhecimento, principalmente quando o conhecimento que procura-se é sobre o estado da arte da pesquisa referente ao um determinado tema, os autores que dão bons resultados, as instituições mais produtivas, as redes cognitivas e suas relações com autoria e coautoria de pesquisadores e IES, encontrando-se pesquisas com abordagem em aplicabilidade de leis bibliométricas, principalmente as Leis de Bradford, Lotka e Zipf.

De acordo com Bogaert, Rousseau e Van Hecke (2000), a Lei de Bradford ou Lei da Dispersão, incide sobre conjunto de periódicos e surgiu por meio de pesquisas que foram conduzidas por Hill Bradford e outros médicos do conselho de pesquisas médicas dos Estados Unidos. Reconhecer a extensão de publicação de artigos científicos de um assunto específico, em revistas especializadas daquele tema era a presunção do estudo de Hill Bradford e dos demais médicos do conselho de pesquisas médicas americano. Machado Junior, Souza, Parisotto e Palmisano (2016) afirmam que, a Lei de Bradford afere qual a relevância de periódicos que dominam as áreas do conhecimento específicas.

A Lei de Lotka (1926) ou Lei do Quadrado Inverso apresenta que um pequeno número de pesquisadores consegue produzir muito em uma área específica de conhecimento, contudo um volume elevado de pesquisadores produz insuficientemente (Machado Júnior et al., 2016).

De acordo com Guedes e Borschiver (2005), a Lei de Zipf ou Lei do Mínimo Esforço, baseia-se na medição de frequência do aparecimento das palavras em diversos textos, estabelecendo dessa forma uma lista composta de termos de um determinado assunto ou disciplina. A lei de Bradford (1934) compara a quantidade de artigos em determinada área à distribuição deles nos periódicos e, de outro modo, a lei de Zipf (1949) posiciona-se como um modelo, associando a classificação do documento em determinada área as palavras-chave (Teixeira, Iwamoto, \& Medeiros, 2013). De forma resumida, vemos na Figura 1, as medidas, critérios e principais objetivos de cada lei que rege os estudos bibliométricos.

\begin{tabular}{c|c|c|l}
\hline Leis & Medida & Critério & \multicolumn{1}{c}{ Objetivo principal } \\
\hline $\begin{array}{c}\text { Lei de } \\
\text { Bradford }\end{array}$ & $\begin{array}{c}\text { Grau de atração } \\
\text { do periódico }\end{array}$ & $\begin{array}{c}\text { Reputação do } \\
\text { periódico }\end{array}$ & $\begin{array}{l}\text { Identificar os periódicos mais relevantes e que dão } \\
\text { maior vazão a um tema em específico }\end{array}$ \\
\hline Lei de Zipf & $\begin{array}{c}\text { Frequência de } \\
\text { palavras-chave }\end{array}$ & $\begin{array}{c}\text { Lista ordenada } \\
\text { de temas }\end{array}$ & $\begin{array}{l}\text { Estimar os temas mais recorrentes relacionados a } \\
\text { um campo de conhecimento }\end{array}$ \\
\hline Lei de Lotka & $\begin{array}{c}\text { Produtividade } \\
\text { autor }\end{array}$ & $\begin{array}{c}\text { Tamanho- } \\
\text { frequência }\end{array}$ & $\begin{array}{l}\text { Levantar o impacto da produção de um autor numa } \\
\text { área de conhecimento }\end{array}$ \\
\hline
\end{tabular}

Figura 1 - Leis que regem os estudos bibliométricos Fonte: Chueke \& Amatucci (2015)

Chueke e Amatucci $(2015$, p. 2) ressaltam ainda que o rigor nos estudos bibliométricos "é caracterizado pelo atendimento das premissas que regem cada um dos métodos. ", como visto nas leis que regem esses estudos.

\section{METODOLOGIA}

Este estudo classifica-se como descritivoquantitativo, uma vez que se utiliza de um levantamento bibliométrico, utilizando-se, para tanto, um conjunto de categorias analíticas, mensuradas objetivamente e apresentadas sob a forma de resultados quantificáveis (Neuman, 2013).

Para analisar a produção científica brasileira sobre $B G$, foram pesquisados nos periódicos de Qualis A1 a B3, referente ao quadriênio 2013-2016, na área de avaliação de "Administração Pública e de Empresas, Ciências Contábeis e Turismo". Esses dados foram posteriormente confirmados por uma pesquisa na base Scientific Periodicals Eletronic Library (SPELL). Além disso, foram pesquisados os anais do Encontro 
da ANPAD (ENANPAD). A pesquisa foi realizada no mês de outubro de 2019, nos portais das revistas, utilizando a busca avançada, com as seguintes palavras-chaves: "born global" $O R$ "born-global" $O R$ "born globals" $O R$ "nascidas globais" $O R$ "nascidas internacionais" OR "instant internationals" OR "international new ventures". Os termos foram pesquisados no título, resumo, abstract ou palavraschave das publicações, sem corte temporal. O estudo bibliométrico permite a avaliação quantitativa e a influência científica do conhecimento em um determinado assunto (van Leeuwen, 2006).

Buscou-se encontrar a evolução das publicações no tema nas seguintes categorias: Periódico, qualis das Revistas, publicações por ano, número de autores por publicação, autores com mais publicações no tema, autores por instituição, artigos por abordagem metodológica, por tipo de pesquisa de pesquisa, por procedimentos técnicos, palavras-chave utilizadas nos artigos e publicação por idioma.
Para a contagem das palavras-chave, foram traduzidas as utilizadas nos artigos de língua não portuguesa, exceto quando se tratava dos termos de buscas específicos, a saber: born global, born-global ou born globals. Este procedimento foi realizado para melhor quantificar as palavras-chave. Os dados encontrados foram tabulados no Microsoft Office Excel.

\section{RESULTADOS E DISCUSSÃO}

Foram identificadas 43 publicações em 18 periódicos diferentes, com o envolvimento de 101 autores e 35 Instituições. Nas figuras a seguir, serão apresentados os resultados da pesquisa de forma mais detalhada. Na Figura 2, são apresentados todos os artigos encontrados, classificados por ano de publicação, mas contendo também a informação do nome do periódico publicado, título do artigo e nomes dos autores.

\begin{tabular}{|c|c|c|c|}
\hline Revista & Título & Autores & Ano \\
\hline ENANPAD & $\begin{array}{l}\text { Drivers da Internacionalização de } \\
\text { Born Globals: Estudo de uma } \\
\text { Empresa de Syndication }\end{array}$ & $\begin{array}{l}\text { Selma Carvalho } \\
\text { Libânia Rangel de Alvarenga Paes }\end{array}$ & 2006 \\
\hline ENANPAD & $\begin{array}{l}\text { Processo de Internacionalização de } \\
\text { Empresas Nascidas Globais: Estudo } \\
\text { de Casos no Setor de Software }\end{array}$ & $\begin{array}{c}\text { Angela da Rocha } \\
\text { Renato Cotta de Mello } \\
\text { Luis Antonio da Rocha Dib } \\
\text { Anne Marie } \\
\text { Maculan }\end{array}$ & 2006 \\
\hline FACES (FACE/FUMEC) & $\begin{array}{l}\text { O Prisma da Internacionalização: Um } \\
\text { Estudo de Caso }\end{array}$ & $\begin{array}{c}\text { Felipe Mendes Borini } \\
\text { Fernanda Cecília Ferreira Ribeiro } \\
\text { Fernanda Peixoto Coelho } \\
\text { Eduardo Rezende Proença }\end{array}$ & 2006 \\
\hline ENANPAD & $\begin{array}{l}\text { Caracterizando o Processo de } \\
\text { Internacionalização Born Global: } \\
\text { Discussão sobre a Conceituação } \\
\text { Empírica do Fenômeno e Hipóteses } \\
\text { de Pesquisa }\end{array}$ & Luís Antônio Dib & 2008 \\
\hline ENANPAD & $\begin{array}{l}\text { Internacionalização Precoce versus } \\
\text { Internacionalização Gradual: um } \\
\text { Estudo sobre Born Globals na } \\
\text { Indústria Brasileira de Software }\end{array}$ & $\begin{array}{l}\text { Luís Antônio Dib } \\
\text { Angela da Rocha }\end{array}$ & 2008 \\
\hline $\begin{array}{l}\text { PRETEXTO (BELO } \\
\text { HORIZONTE) }\end{array}$ & $\begin{array}{l}\text { Internacionalização das Empresas de } \\
\text { Biotecnologia em Belo Horizonte - } \\
\text { MG, Brasil. }\end{array}$ & $\begin{array}{c}\text { Otavio Rezende } \\
\text { Cristiane Amaral Serpa }\end{array}$ & 2008 \\
\hline ENANPAD & $\begin{array}{l}\text { Empresas Born Globals Brasileiras: a } \\
\text { Influência do Perfil do Empreendedor } \\
\text { e da Localização Geográfica }\end{array}$ & $\begin{array}{l}\text { Fernanda Cecília Ferreira Ribeiro } \\
\text { João Eduardo Albino Pimentel }\end{array}$ & 2009 \\
\hline $\begin{array}{c}\text { Revista Ibero-Americana } \\
\text { de Estratégia }\end{array}$ & $\begin{array}{l}\text { Las Capacidades en Tecnologias de la } \\
\text { Información y las Firmas Born Globals }\end{array}$ & $\begin{array}{c}\text { Maria Soledad Etchebarne Lópes } \\
\text { Valeska Viola Geldres Weiss } \\
\text { Heidy Rodriguez Ramos }\end{array}$ & 2009 \\
\hline
\end{tabular}




\begin{tabular}{|c|c|c|c|}
\hline Gestão \& Regionalidade & $\begin{array}{l}\text { Internacionalização de Pequenas } \\
\text { Empresas: U Estudo de Caso com } \\
\text { uma Empresa Brasileira de } \\
\text { Tecnologia }\end{array}$ & $\begin{array}{l}\text { Renata Céli Moreira da Silva; Marie } \\
\text { Agnes Chauvel; Hélène Bertrand }\end{array}$ & 2010 \\
\hline ENANPAD & 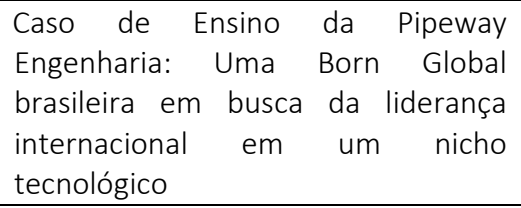 & $\begin{array}{c}\text { Marcelo Presa Costa } \\
\text { Lygia Alessandra Magalhães Magacho } \\
\text { Jorge Carneiro }\end{array}$ & 2010 \\
\hline $\begin{array}{l}\text { INTERNEXT - REVISTA } \\
\text { ELETRÔNICA DE } \\
\text { NEGÓCIOS } \\
\text { INTERNACIONAIS }\end{array}$ & $\begin{array}{l}\text { O Processo de Internacionalização de } \\
\text { uma Empresa de Software para } \\
\text { Moda: Da Incubadora ao } \\
\text { Investimento Direto no Exterior }\end{array}$ & $\begin{array}{c}\text { William Ramosi } \\
\text { Graziela Dias Alperstedtii }\end{array}$ & 2010 \\
\hline $\begin{array}{l}\text { RAI : REVISTA DE } \\
\text { ADMINISTRAÇÃO E } \\
\text { INOVAÇÃO }\end{array}$ & $\begin{array}{l}\text { Importância das Redes nos Processos } \\
\text { de Inovação e Internacionalização de } \\
\text { Empresas de Base Tecnológica }\end{array}$ & $\begin{array}{l}\text { Ilisangela Mais } \\
\text { Luciano Castro de Carvalho } \\
\text { Mohamed Amal } \\
\text { Micheline Gaia Hoffmann }\end{array}$ & 2010 \\
\hline ENANPAD & $\begin{array}{l}\text { A Integração entre Diferentes } \\
\text { Abordagens Comportamentais e o } \\
\text { Processo de Internacionalização de } \\
\text { uma Born Global com mais de uma } \\
\text { Década de Existência: Estudo do Caso } \\
\text { Mercado Libre na América Latina e } \\
\text { Península Ibérica }\end{array}$ & $\begin{array}{l}\text { Felipe Magalhães Bohrer } \\
\text { Luís Antônio Dib }\end{array}$ & 2011 \\
\hline $\begin{array}{l}\text { REVISTA DA MICRO E } \\
\text { PEQUENA EMPRESA } \\
\text { (FACCAMP) }\end{array}$ & $\begin{array}{l}\text { Internacionalização de Micro e } \\
\text { Pequenas Empresas: Um Estudo de } \\
\text { Caso Sobre a Atuação do SEBRAE. }\end{array}$ & $\begin{array}{c}\text { Teodoro Malta Campos } \\
\text { Edmilson de Oliveira Lima } \\
\text { Vladas Urbanavicius Júnior } \\
\text { Danilo Vieira Alves }\end{array}$ & 2011 \\
\hline $\begin{array}{l}\text { INTERNEXT - REVISTA } \\
\text { ELETRÔNICA DE } \\
\text { NEGÓCIOS } \\
\text { INTERNACIONAIS }\end{array}$ & $\begin{array}{l}\text { O Processo de Internacionalização de } \\
\text { Empresas de Software: O Caso } \\
\text { Audaces }\end{array}$ & $\begin{array}{c}\text { Antonia Egidia Souza } \\
\text { Eduardo Pinheiro Gondim } \\
\text { Vasconcello } \\
\text { Harmilton Luiz Corrêa }\end{array}$ & 2012 \\
\hline $\begin{array}{c}\text { REVISTA DE } \\
\text { ADMINISTRAÇÃO } \\
\text { CONTEMPORÂNEA }\end{array}$ & $\begin{array}{l}\text { Internacionalização Acelerada de } \\
\text { Empresas de Base Tecnológica: o } \\
\text { Caso das Born Globals Brasileiras }\end{array}$ & $\begin{array}{l}\text { Fernanda Ferreira Ribeiro } \\
\text { Moacir Miranda Oliveira Jr. } \\
\text { Felipe Mendes Borini }\end{array}$ & 2012 \\
\hline ENANPAD & $\begin{array}{l}\text { Internacionalização Acelerada de } \\
\text { Empresas de Base Tecnológica: As } \\
\text { born globals brasileiras }\end{array}$ & $\begin{array}{c}\text { Fernanda Cecilia Ferreira Ribeiro } \\
\text { Moacir de Miranda Oliveira Junior } \\
\text { Felipe Mendes Borini }\end{array}$ & 2012 \\
\hline $\begin{array}{c}\text { Revista de Administração } \\
\text { da UFSM }\end{array}$ & $\begin{array}{l}\text { O Papel da Internet em Empresas } \\
\text { Nascidas Globais }\end{array}$ & 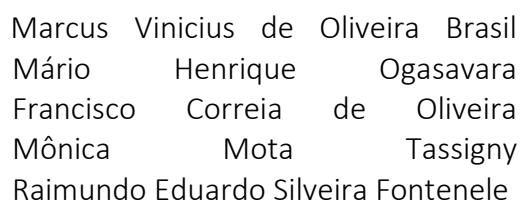 & 2013 \\
\hline FACES (FACE/FUMEC) & $\begin{array}{l}\text { Reconciliando o Modelo de Uppsala } \\
\text { com Perspectiva de Networks: } \\
\text { Revisão Crítica e Integrativa }\end{array}$ & $\begin{array}{l}\text { Carlos Augusto Septímio de Carvalho } \\
\text { Luís Antônio da Rocha Dib }\end{array}$ & 2013 \\
\hline $\begin{array}{c}\text { REVISTA DE } \\
\text { ADMINISTRAÇÃO DA } \\
\text { UFSM }\end{array}$ & $\begin{array}{l}\text { The Role OF Internet in the Born } \\
\text { Global Companies }\end{array}$ & $\begin{array}{c}\text { Marcus Vinicius de Oliveira Brasil } \\
\text { Mario Henrique Ogasavara } \\
\text { Francisco Correia de Oliveira } \\
\text { Mônica Mota Tassigny } \\
\text { Raimundo Eduardo Silveira Fontenele }\end{array}$ & 2013 \\
\hline
\end{tabular}




\begin{tabular}{|c|c|c|c|}
\hline ALCANCE (UNIVALI) & $\begin{array}{l}\text { O Processo de Internacionalização de } \\
\text { Empresas de Comércio Eletrônico } \\
\text { Sob o Olhar Comportamental: Estudo } \\
\text { Longitudinal dos Casos MercadoLivre } \\
\text { e Ebay }\end{array}$ & $\begin{array}{l}\text { Felipe Magalhães Bohrer } \\
\text { Luís Antônio da Rocha Dib }\end{array}$ & 2014 \\
\hline ENANPAD & $\begin{array}{l}\text { Building Asymmetric Symbiotic } \\
\text { Relationships: International New } \\
\text { Ventures and the Multinational } \\
\text { Networks }\end{array}$ & $\begin{array}{c}\text { Angela Maria Cavalcanti da Rocha } \\
\text { Melissa Wilson Senra } \\
\text { Jorge Ferreira da Silva } \\
\text { Renato Dourado Cotta de Mello } \\
\text { Luciana Albuquerque Alves }\end{array}$ & 2015 \\
\hline GESTÃO \& PRODUÇÃO & $\begin{array}{l}\text { Tecnologia e trajetórias de } \\
\text { Internacionalização } \\
\text { precoce: análise de casos na indústria } \\
\text { brasileira }\end{array}$ & $\begin{array}{c}\text { Andresa Silva Neto Francischini } \\
\text { João Furtado } \\
\text { Renato Garcia }\end{array}$ & 2015 \\
\hline $\begin{array}{l}\text { REVISTA IBERO- } \\
\text { AMERICANA DE } \\
\text { ESTRATÉGIA }\end{array}$ & $\begin{array}{l}\text { Diferentes Abordagens Conceptuais } \\
\text { Sobre a Internacionalização das } \\
\text { Empresas: Uma Revisão Bibliométrica }\end{array}$ & $\begin{array}{l}\text { João Carvalho Santos } \\
\text { Hortênsia Karl Barandas } \\
\text { Francisco Vitorino Martins }\end{array}$ & 2015 \\
\hline RAUSP & $\begin{array}{l}\text { Orientação Internacional e } \\
\text { Comprometimento Exportador na } \\
\text { Rápida Internacionalização de } \\
\text { Pequenas e Médias Empresas: } \\
\text { Validação de Escalas e Implicações } \\
\text { para o Caso Brasileiro }\end{array}$ & $\begin{array}{l}\text { Marcelo André Machado } \\
\text { Walter Meucci Nique } \\
\text { Felipe Bentancur Fehse }\end{array}$ & 2016 \\
\hline $\begin{array}{c}\text { REVISTA DE } \\
\text { ADMINISTRAÇÃO } \\
\text { CONTEMPORÂNEA }\end{array}$ & $\begin{array}{l}\text { Interdependence Across a Firm's } \\
\text { International Trajectories }\end{array}$ & $\begin{array}{c}\text { Andre Limp } \\
\text { Sérgio Fernando Loureiro Rezende } \\
\text { Angela Versiani }\end{array}$ & 2016 \\
\hline $\begin{array}{c}\text { REVISTA DE } \\
\text { ADMINISTRAÇÃO DA } \\
\text { UNIVERSIDADE DE SÃO } \\
\text { PAULO (1947) }\end{array}$ & $\begin{array}{l}\text { International orientation and export } \\
\text { commitment in fast small and } \\
\text { medium size firms } \\
\text { internationalization: scales validation } \\
\text { and implications for the Brazilian case }\end{array}$ & $\begin{array}{l}\text { Marcelo André Machado } \\
\text { Walter Meucci Nique } \\
\text { Felipe Bentancur Fehse }\end{array}$ & 2016 \\
\hline $\begin{array}{l}\text { REVISTA GESTAO \& } \\
\text { DESENVOLVIMENTO }\end{array}$ & $\begin{array}{l}\text { Análise Reflexiva do Processo de } \\
\text { internacionalização das Empresas de } \\
\text { Negócios Digitais }\end{array}$ & $\begin{array}{c}\text { Mateus Feld } \\
\text { Dusan Schreiber }\end{array}$ & 2016 \\
\hline ENANPAD & $\begin{array}{l}\text { Institutions, Networks and the } \\
\text { International Growth of Born Globals } \\
\text { from Emerging Markets }\end{array}$ & $\begin{array}{c}\text { Thaisa Carolina Zonta } \\
\text { Mohamed Amal }\end{array}$ & 2017 \\
\hline CADERNOS EBAPE.BR & $\begin{array}{l}\text { Escolas Teóricas do Processo de } \\
\text { Internacionalização: Uma Visão } \\
\text { Epistemológica }\end{array}$ & $\begin{array}{c}\text { Lúcia de Fátima Lúcio Gomes da Costa } \\
\text { Miguel Eduardo Moreno Añez } \\
\text { Anderson Luiz Rezende Mol } \\
\text { Thiago dos Santos Azevedo } \\
\text { Damasceno }\end{array}$ & 2017 \\
\hline $\begin{array}{l}\text { INTERNEXT - REVISTA } \\
\text { ELETRÔNICA DE } \\
\text { NEGÓCIOS } \\
\text { INTERNACIONAIS }\end{array}$ & $\begin{array}{l}\text { Dimensions on born-global firms' } \\
\text { case studies }\end{array}$ & $\begin{array}{c}\text { Ananda Carvalho Pimenta } \\
\text { Marcus Joswig } \\
\text { Moacir de Miranda Oliveira Junior } \\
\text { Roberto Sbragia }\end{array}$ & 2017 \\
\hline $\begin{array}{c}\text { REVISTA DE } \\
\text { ADMINISTRAÇÃO DA } \\
\text { UNIVERSIDADE DE SÃO } \\
\text { PAULO (1947) }\end{array}$ & $\begin{array}{l}\text { Customer relationships } \text { and } \\
\text { interdependences in the } \\
\text { internationalization process of the } \\
\text { firm }\end{array}$ & $\begin{array}{c}\text { André Limp } \\
\text { Sérgio Fernando Loureiro Rezende } \\
\text { Ângela França Versiani }\end{array}$ & 2017 \\
\hline
\end{tabular}




\begin{tabular}{|c|c|c|c|}
\hline $\begin{array}{l}\text { REVISTA GESTÃO \& } \\
\text { TECNOLOGIA }\end{array}$ & $\begin{array}{l}\text { Internacionalização da inovação: um } \\
\text { estudo com empresas de base } \\
\text { tecnológica }\end{array}$ & $\begin{array}{l}\text { Jose Roberto Souza Pascoal } \\
\text { Priscila Rezende Da Costa }\end{array}$ & 2017 \\
\hline $\begin{array}{l}\text { REVISTA IBERO- } \\
\text { AMERICANA DE } \\
\text { ESTRATÉGIA }\end{array}$ & $\begin{array}{l}\text { What Impacts the Performance of } \\
\text { Technology Organization? An } \\
\text { Entreprenerial Perspective }\end{array}$ & $\begin{array}{l}\text { Airan Arinê Possamai } \\
\text { Marianne Hoeltgebaum } \\
\text { Tales Andreassi } \\
\text { Mohamed Amal }\end{array}$ & 2017 \\
\hline $\begin{array}{l}\text { REVISTA BRASILEIRA DE } \\
\text { ADMINISTRAÇÃO } \\
\text { CIENTÍFICA }\end{array}$ & $\begin{array}{l}\text { Estado da produção científica } \\
\text { internacional em Born Globals }\end{array}$ & $\begin{array}{c}\text { Issa Ibrahim Berchin } \\
\text { Alexsandro da Silva } \\
\text { Graciella Martignago } \\
\text { Wlamir Gonçalves Xavier } \\
\text { Ana Barbara Silveira Mendonça } \\
\text { Santos Dias } \\
\text { José Baltazar Salgueirinho Osorio de } \\
\text { Andrade Guerra }\end{array}$ & 2017 \\
\hline ENANPAD & $\begin{array}{l}\text { Empresas Born Global Emergentes: } \\
\text { Um Estudo de Caso sobre a Zee-Dog. }\end{array}$ & $\begin{array}{c}\text { Marcos lazzetti } \\
\text { Eva Farah } \\
\text { Sandra Maira Siqueira Naves Leite }\end{array}$ & 2018 \\
\hline ENANPAD & $\begin{array}{l}\text { The Influence of the Networking in } \\
\text { the Speed of Internationalization } \\
\text { Within the Life Cycle of a Swedish } \\
\text { Born Global Company }\end{array}$ & $\begin{array}{l}\text { Caroline Kretschmer } \\
\text { Ivan Lapuente Garrido } \\
\text { Izabel R. de Souza } \\
\text { Iva Maria Beleti Cardinal }\end{array}$ & 2018 \\
\hline ALCANCE (UNIVALI) & $\begin{array}{l}\text { The Born Global Firms in Brazil and } \\
\text { the Role of Export-Promotion } \\
\text { Programs }\end{array}$ & $\begin{array}{l}\text { Marcelo André Machado } \\
\text { Viviane Bischoff }\end{array}$ & 2018 \\
\hline $\begin{array}{l}\text { INTERNEXT - REVISTA } \\
\text { ELETRÔNICA DE } \\
\text { NEGÓCIOS } \\
\text { INTERNACIONAIS }\end{array}$ & $\begin{array}{l}\text { Internationalization and innovation: } \\
\text { The case of a born global from Brazil }\end{array}$ & $\begin{array}{c}\text { Thaisa Carolina Zonta } \\
\text { Mohamed Amal }\end{array}$ & 2018 \\
\hline $\begin{array}{c}\text { BBR - Brazilian Business } \\
\text { Review }\end{array}$ & $\begin{array}{c}\text { Gerenciamento de Riscos em Born } \\
\text { globals: o caso das Cervejarias } \\
\text { Artesanais Brasileiras }\end{array}$ & Fabricio Stocker ; Gustavo Abib & 2019 \\
\hline FGV EBAPE & $\begin{array}{l}\text { Dynamic networks in early } \\
\text { international agrobusiness }\end{array}$ & Christiam Mendez Lazarte & 2019 \\
\hline ENANPAD & $\begin{array}{l}\text { Capacidades Dinâmicas no contexto } \\
\text { das Born Global ou International } \\
\text { New Ventures: uma Revisão } \\
\text { Sistemática da literatura }\end{array}$ & $\begin{array}{c}\text { Bartira Pereira Amorim } \\
\text { Ana Eliza Galvão Cortez } \\
\text { Anatália Saraiva Martins Ramos } \\
\text { Dinara Leslye Macedo e Silva } \\
\text { Calanzans } \\
\text { Caroline de Albuquerque Mourão } \\
\text { Alves }\end{array}$ & 2019 \\
\hline ENANPAD & $\begin{array}{c}\text { Factores que influyen a las empresas } \\
\text { Born Global de economías } \\
\text { emergentes en el logro de una } \\
\text { internacionalización temprana }\end{array}$ & $\begin{array}{c}\text { Francesca Cardenas Sifuentes } \\
\text { Claudia Chiroque Bruno } \\
\text { Valeria Zhiamen Loo Tay } \\
\text { Martín Hernani-Merino }\end{array}$ & 2019 \\
\hline
\end{tabular}

Figura 2 - Achados da pesquisa

Fonte: Dados da pesquisa (2019)

Na Figura 3 a seguir, são apresentados os nomes dos 18 periódicos e o ENANPAD com publicação sobre o tema. A revista INTERNEXT apresenta-se em primeiro lugar, com quatro publicações, sendo esta revista do Programa de Mestrado e Doutorado em Gestão Internacional da Escola Superior de
Propaganda e Marketing (ESPM), situada em São Paulo. Logo em seguida, consta a revista IberoAmericana de Estratégia, da Universidade Nove de Julho - UNINOVE, também de São Paulo, sendo ambas com Qualis B2. 


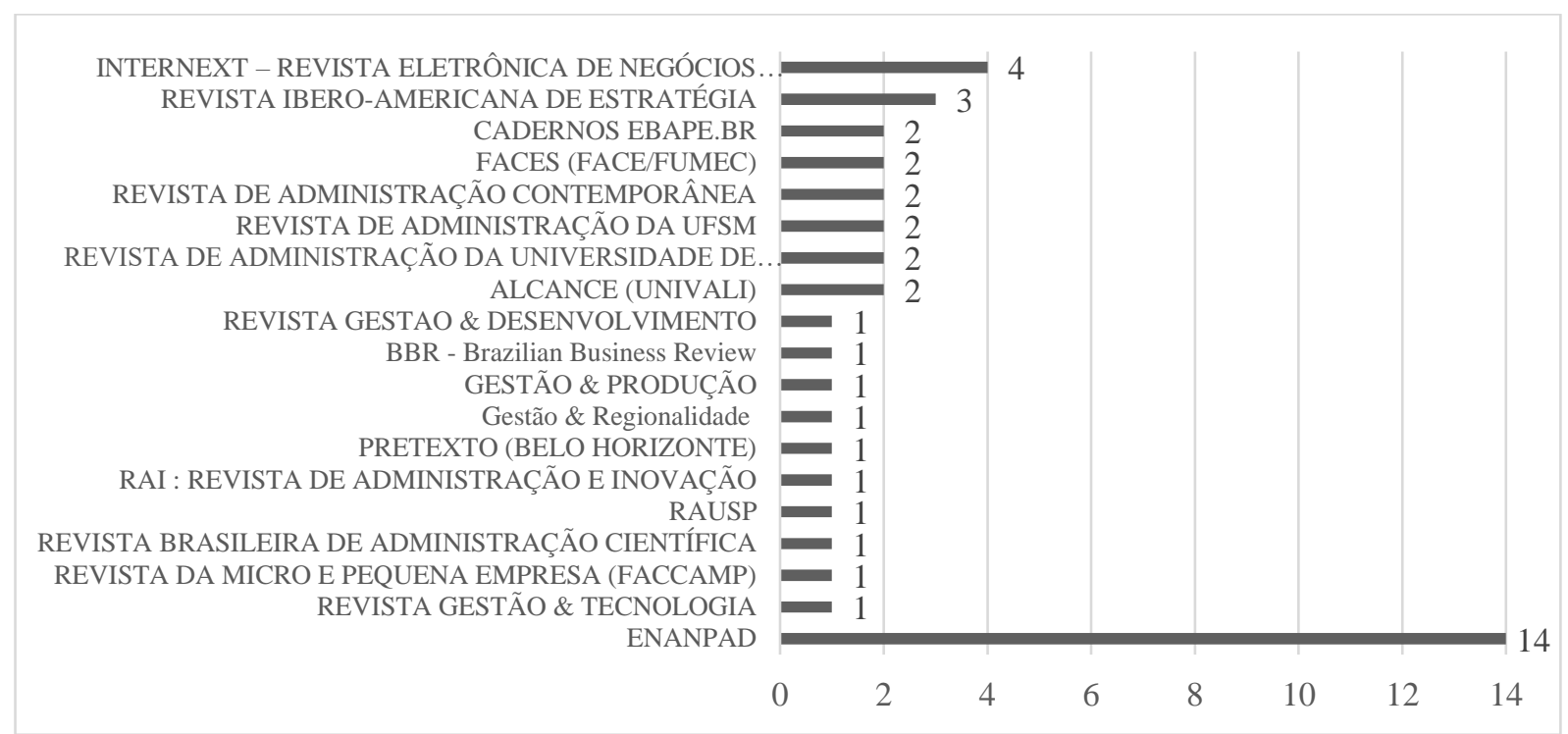

Figura 3 - Número de publicações por periódicos

Fonte: Dados da pesquisa (2019)

Em relação ao Qualis dos periódicos, excluindo-se - ENANPAD, percebe-se que $27,6 \%(n=8)$ das 29 publicações encontradas foram em qualis $A 2$, em seguida $13,8 \% \quad(n=4)$ em qualis $B 1$, uma maior concentração de publicações em qualis B2, com $51,7 \%(n=15)$ e apenas 6,9\% ( $n=2)$ em qualis $A 3$, dentre as 29 encontradas, como apresentado na Figura 5.

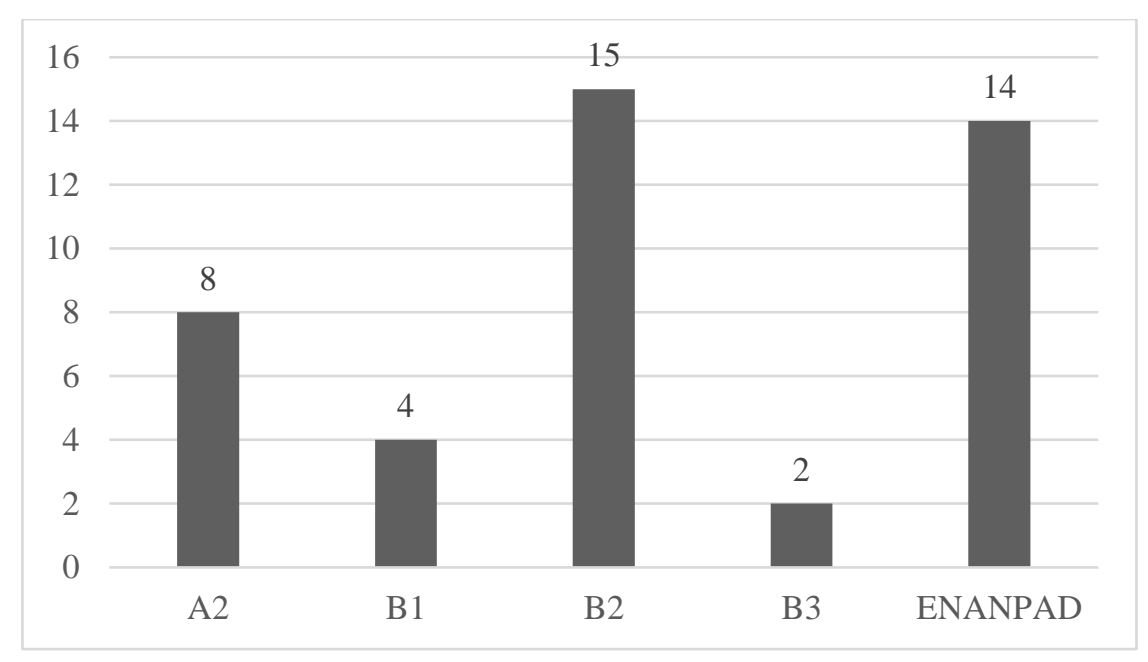

Figura 4 - Número de publicações por Qualis

Fonte: Dados da pesquisa (2019)

Em relação ao número de publicações por ano, percebe-se na Figura 5 que as primeiras publicações sobre o tema, nos periódicos nacionais, se deram apenas em 2006, variando entre uma e quatro publicações entre 2008 e 2016 e dando um salto, com sete publicações, no ano de 2017, seguindo com quatro em 2018 e 2019, até outubro de 19.
A primeira publicação em um periódico brasileiro, feita na revista FACES (FACE/FUMEC) pelos autores Felipe Mendes Borini, Fernanda Cecília Ferreira Ribeiro, Fernanda Peixoto Coelho e Eduardo Rezende Proença, todos da PUC-SP à época da publicação. As demais publicações de 2006, foram nos anais do ENANPAD. 


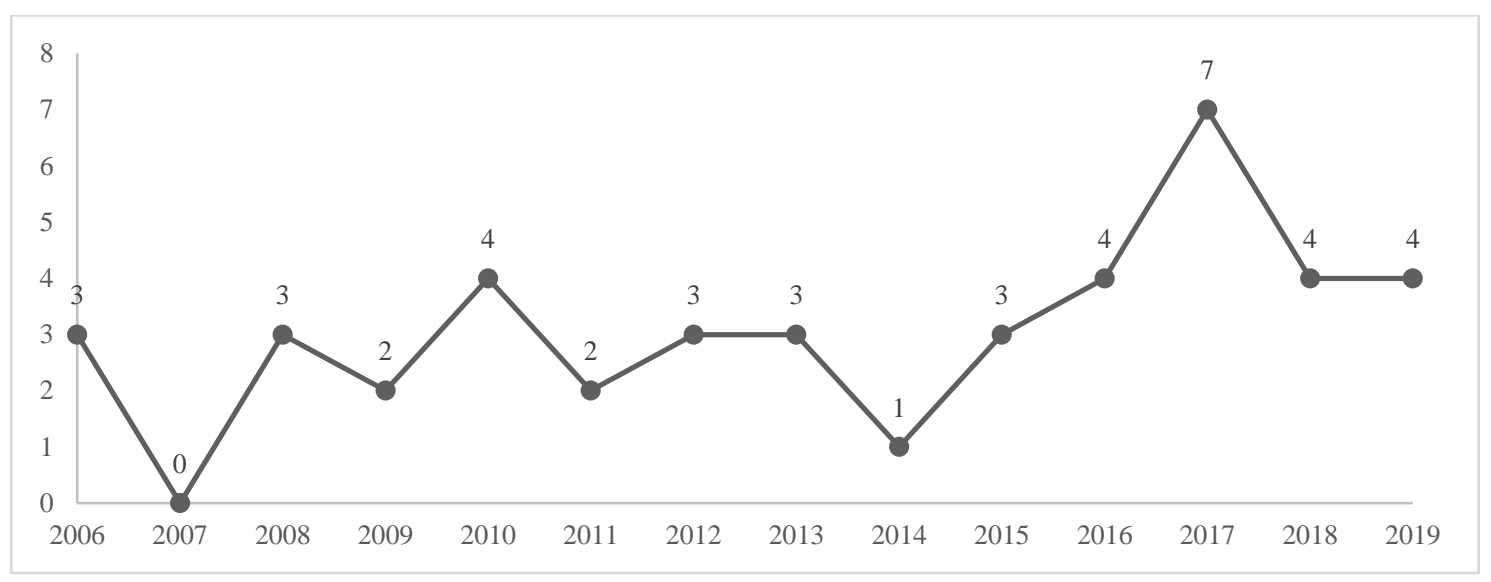

Figura 5 - Número de publicações por ano Fonte: Dados da pesquisa (2019)

Na Figura 6, tem-se o número autores por publicação e percebe-se um destaque para o quantitativo de dois e três autores por publicação, sendo que apenas duas foram feitas por apenas um autor, o que sugere que as pesquisas são provenientes de autor e orientador, equipes em disciplinas e grupos de pesquisa.

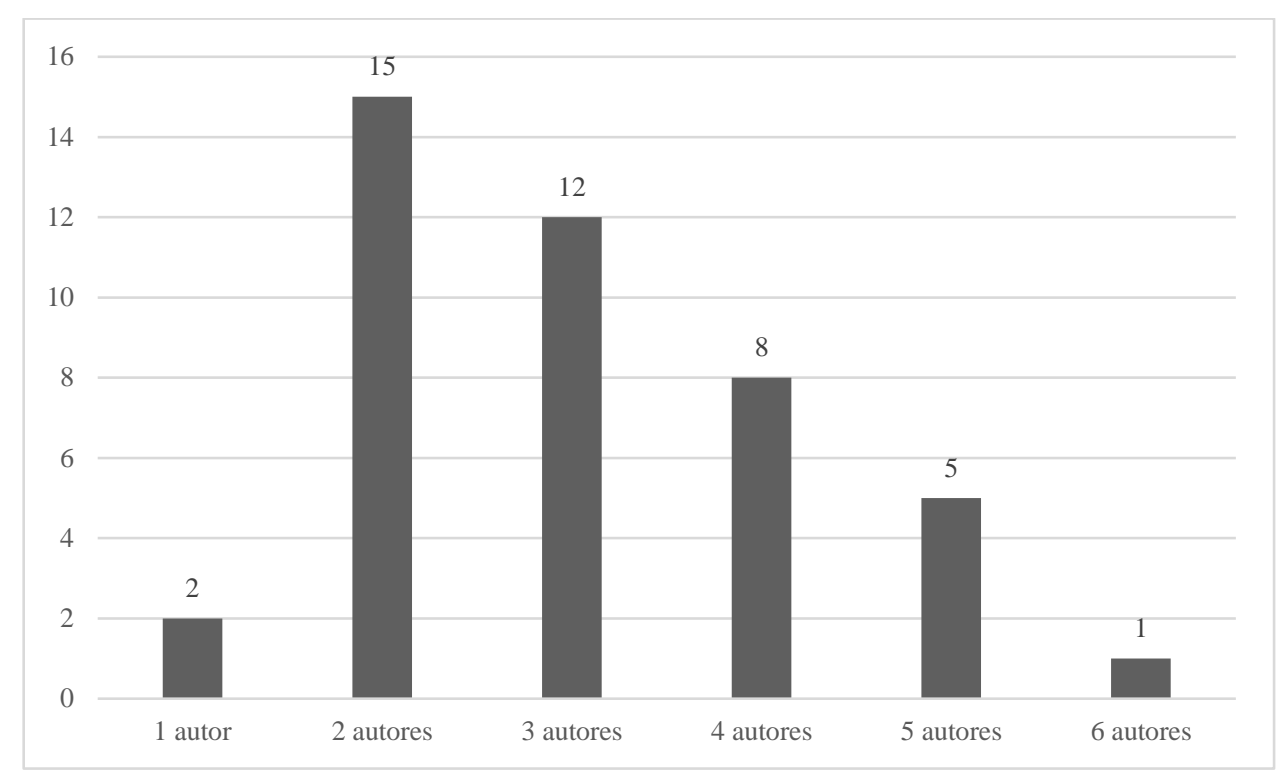

Figura 6 - Número autores por publicação Fonte: Dados da pesquisa (2019)

Em relação aos autores com publicações sobre o tema, a Figura 7 apresenta os nomes dos autores com pelo menos três publicações. O autor Luís Antônio da
Rocha Dib se destaca com seis publicações sobre o tema. 


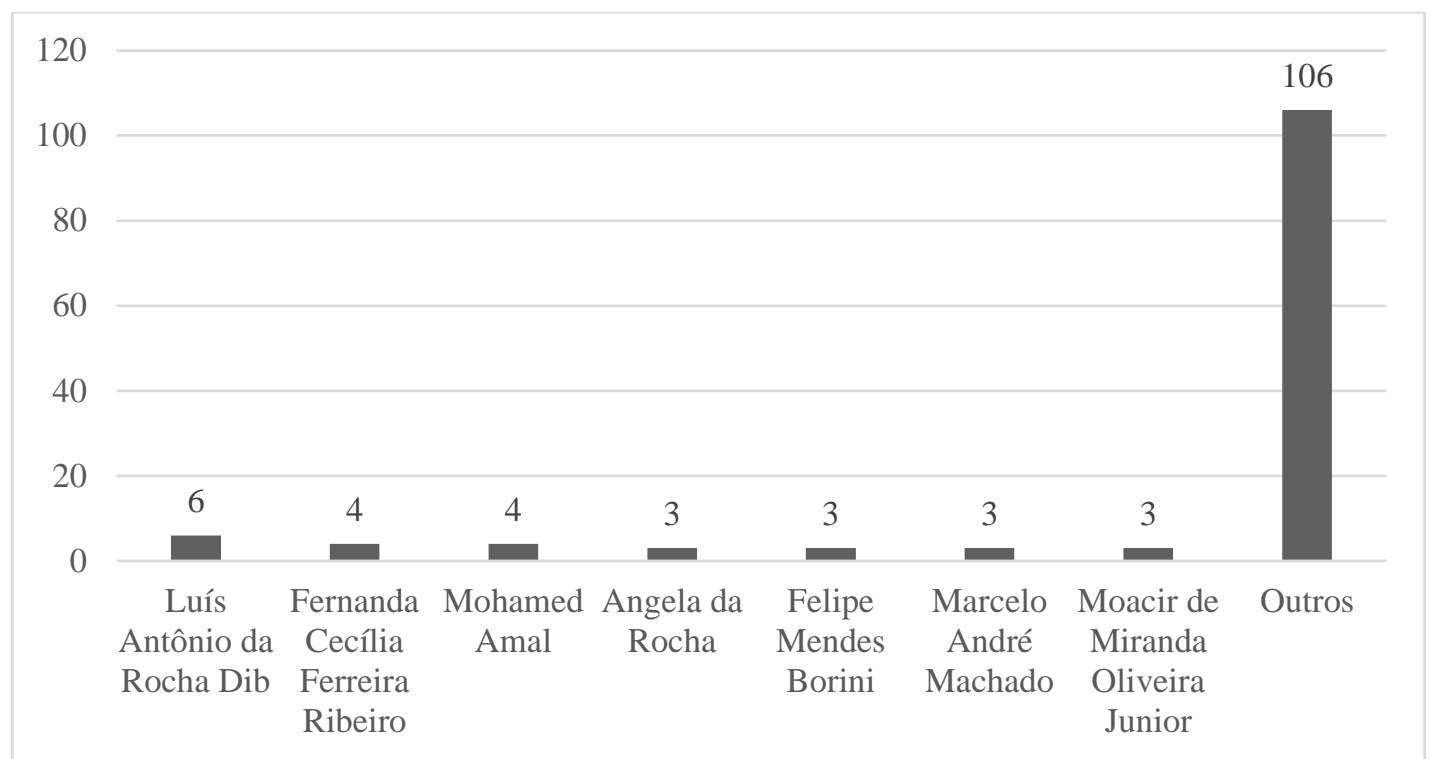

Figura 7 - Autores com mais publicações no tema.

Fonte: Dados da pesquisa (2019)

Como já mencionado, participaram um total de 101 autores sendo que 94 deles possuem apenas uma ou duas publicações cada, como apresentado na Figura 8 . O somatório do número de participações em publicações por autor é de 132. Como medida na Lei de Lotka (Chueke \& Amatucci, 2015), esta análise atende ao seu critério e objetivo principal.

\begin{tabular}{|c|l|c|c|}
\hline \multicolumn{2}{|c|}{ Nome do autor } & No participações & $\begin{array}{c}\text { Porcentagem } \\
\text { de participações }\end{array}$ \\
\hline 1 & Luís Antônio da Rocha Dib & 6 & $4,5 \%$ \\
\hline 2 & Fernanda Cecília Ferreira Ribeiro & 4 & $3,0 \%$ \\
\hline 3 & Mohamed Amal & 4 & $3,0 \%$ \\
\hline 4 & Angela da Rocha & 3 & $2,3 \%$ \\
\hline 5 & Felipe Mendes Borini & 3 & $2,3 \%$ \\
\hline 6 & Marcelo André Machado & 3 & $2,3 \%$ \\
\hline 7 & Moacir de Miranda Oliveira Junior & - & $2,3 \%$ \\
\hline 8 & Outros 94 autores & $30,3 \%$ \\
\hline
\end{tabular}

Figura 8 - Relação de autores com participações em publicações

Fonte: Dados da pesquisa (2019)

A Figura 9 apresenta o número de autores com publicações sobre o tema, por Instituição, com destaque para a FURB de Santa Catarina com nove e a USP de São Paulo com oito, além da UNISINOS/RS e a UFRN/RN, ambas com oito autores cada. 


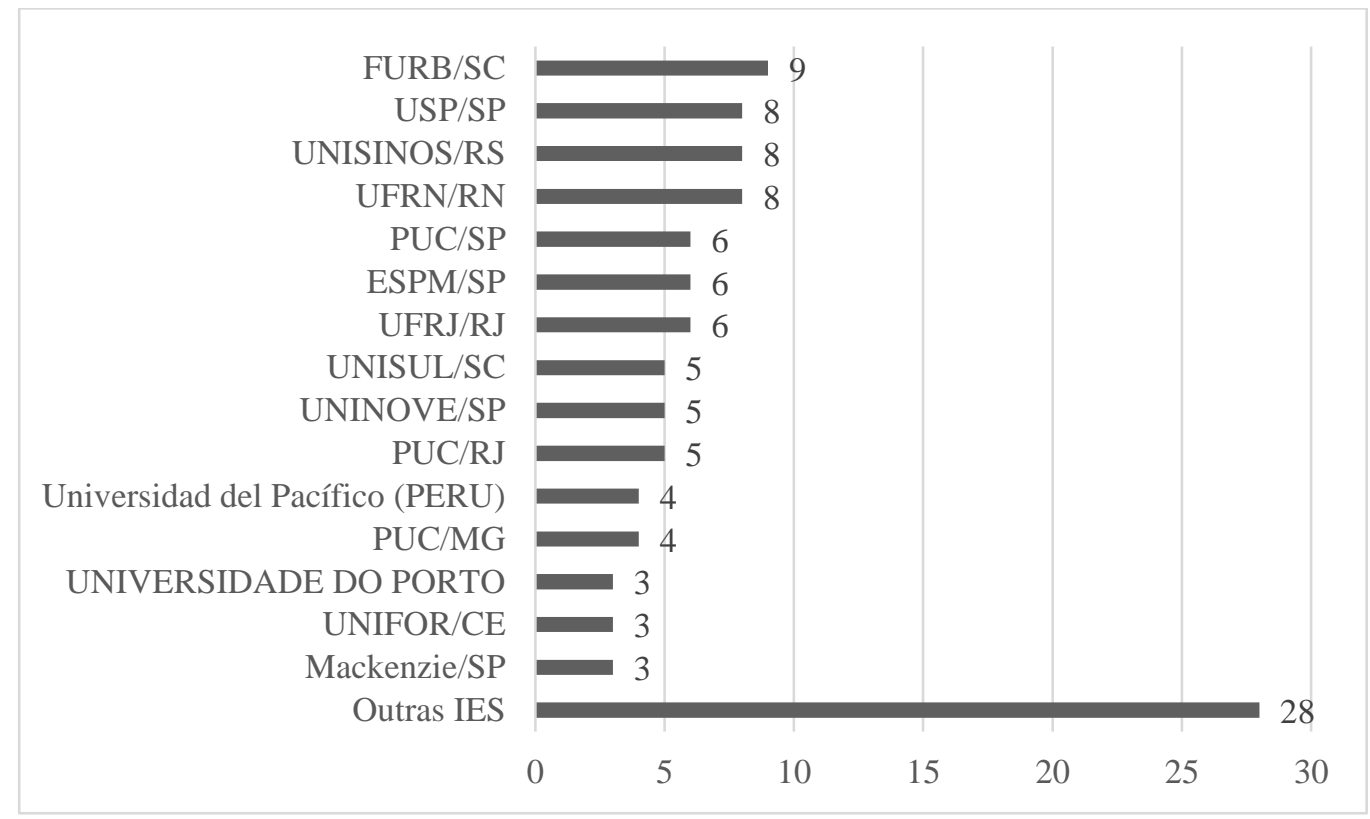

Figura 9 - Número de autores com publicações sobre o tema, por instituição. Fonte: Dados da pesquisa (2019)

Em relação aos tipos de abordagens metodológica dos artigos, a Figura 10, apresenta que 69,0\% ( $n=29)$ deles são de abordagem qualitativa, enquanto que $26,2 \%(n=11)$ são quantitativos e apenas 4,8\% (n=2) se apresentou como misto entre as abordagens qualitativa e quantitativa, o que sugere que as pesquisas no Brasil precisam evoluir com dados estatísticos, podendo-se inferir que a produção brasileira no tema ainda está em crescimento.

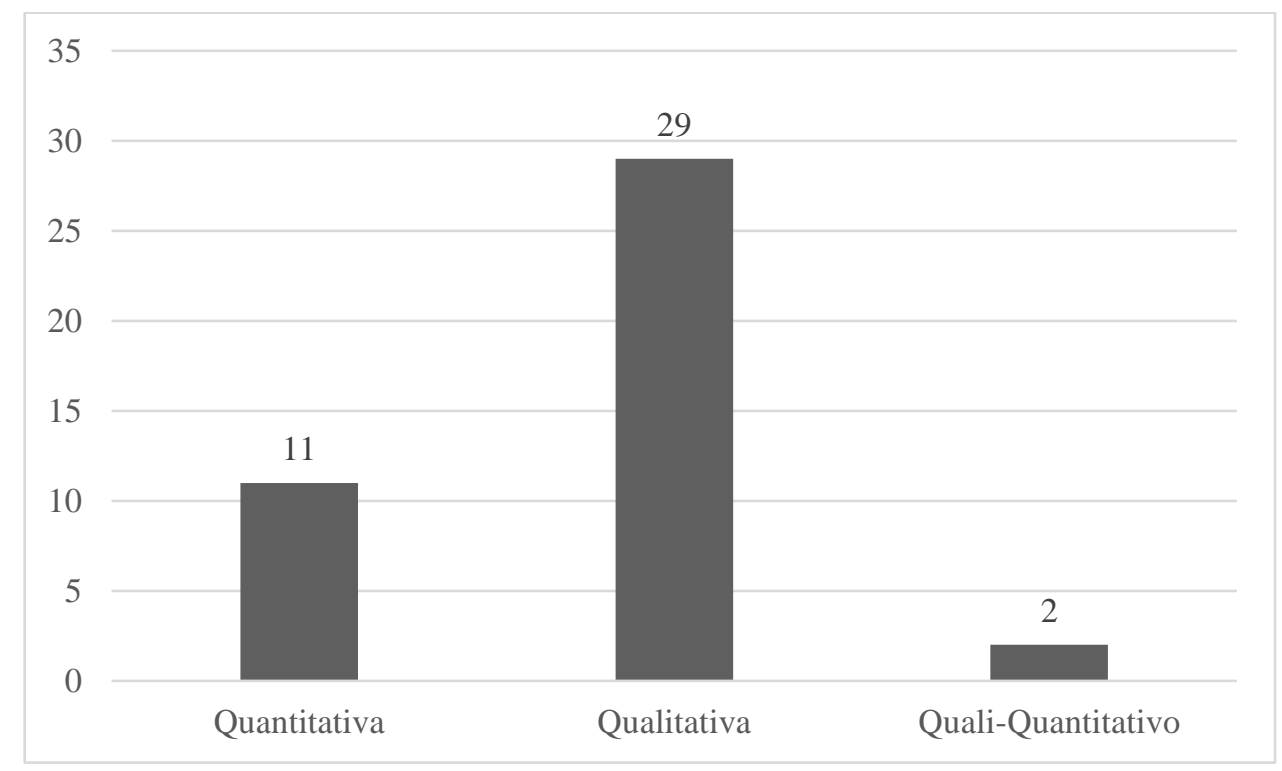

Figura 10 - Número de artigos por abordagem

Fonte: Dados da pesquisa (2019)

Quanto aos tipos de pesquisa, de acordo com Gil (2007), é possível classificar as pesquisas em pesquisa exploratória, pesquisa descritiva e pesquisa explicativa. Seguindo esta classificação, os achados da pesquisa podem ser assim representados, como mostra a Figura 11. 


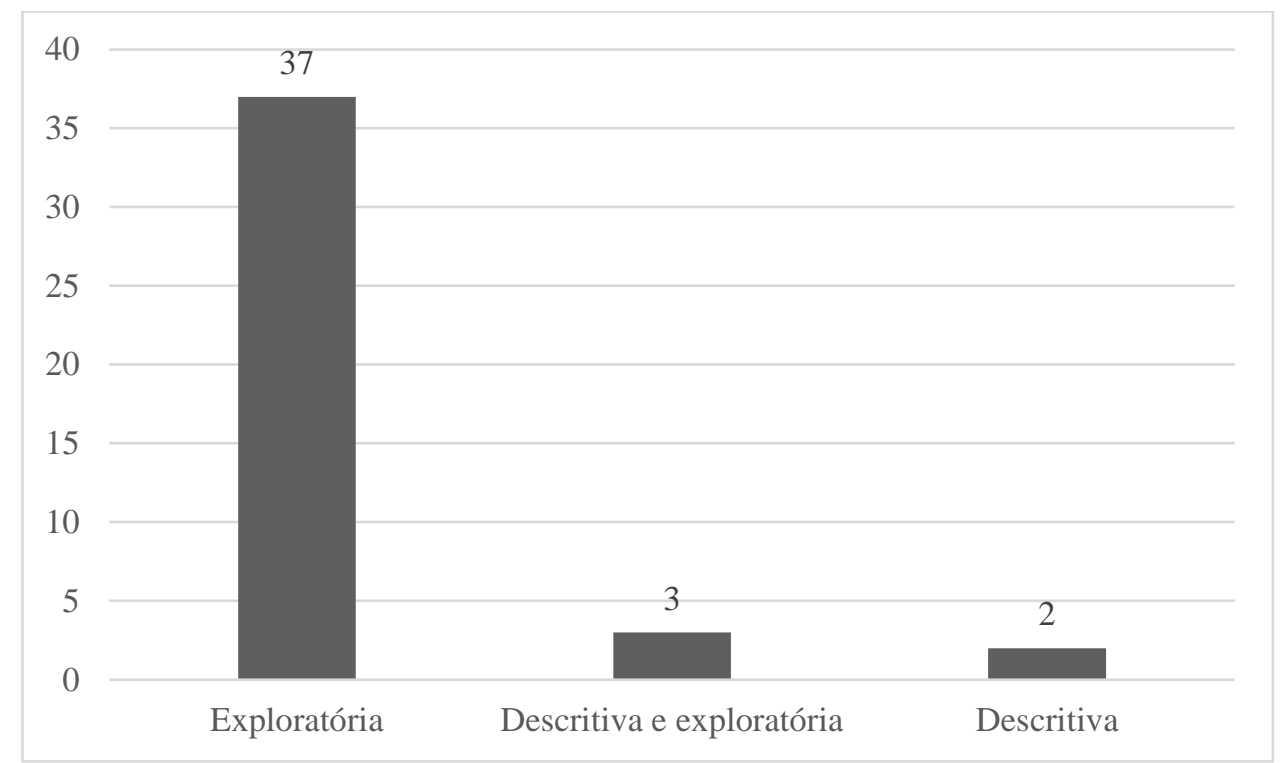

Figura 11 - Classificação dos artigos por tipo de pesquisa

Fonte: Dados da pesquisa (2019)

Percebe-se uma grande preferência pela pesquisa com objetivo exploratório, já que este tipo de pesquisa tem como objetivo proporcionar maior familiaridade com o problema, com vistas a torná-lo mais explícito ou a construir hipóteses (Gil, 2007). Isso corrobora com as inferências dos estudos qualitativos anteriormente relatados e ainda que mesmo que se tenha quatro artigos quantitativos, nenhum deles utilizou método inferencial de análise univariada ou multivariada, com abordagem explicativa.

No que diz respeito aos procedimentos técnicos adotados pelos achados da pesquisa, a Figura 12 apresenta que o procedimento estudo de caso é o mais utilizado nos artigos, com 21 artigos dos 43 encontrados, seguido por Revisão de literatura, revisão sistemática (de literatura) e Estudo de casos multíplos. Estas últimas são essenciais para o desenvolvimento das teorias de BG, uma vez que o tema ainda possui definições e conceitos diversos dentro da academia, como já mostrado no referencial teórico. O desenvolvimento da literatura em BG pode abrir um campo maior para a criação de novos modelos para estudos e testes na área, além de estabelecer uma unidade de conceitos importante para a consolidação dessas empresas.

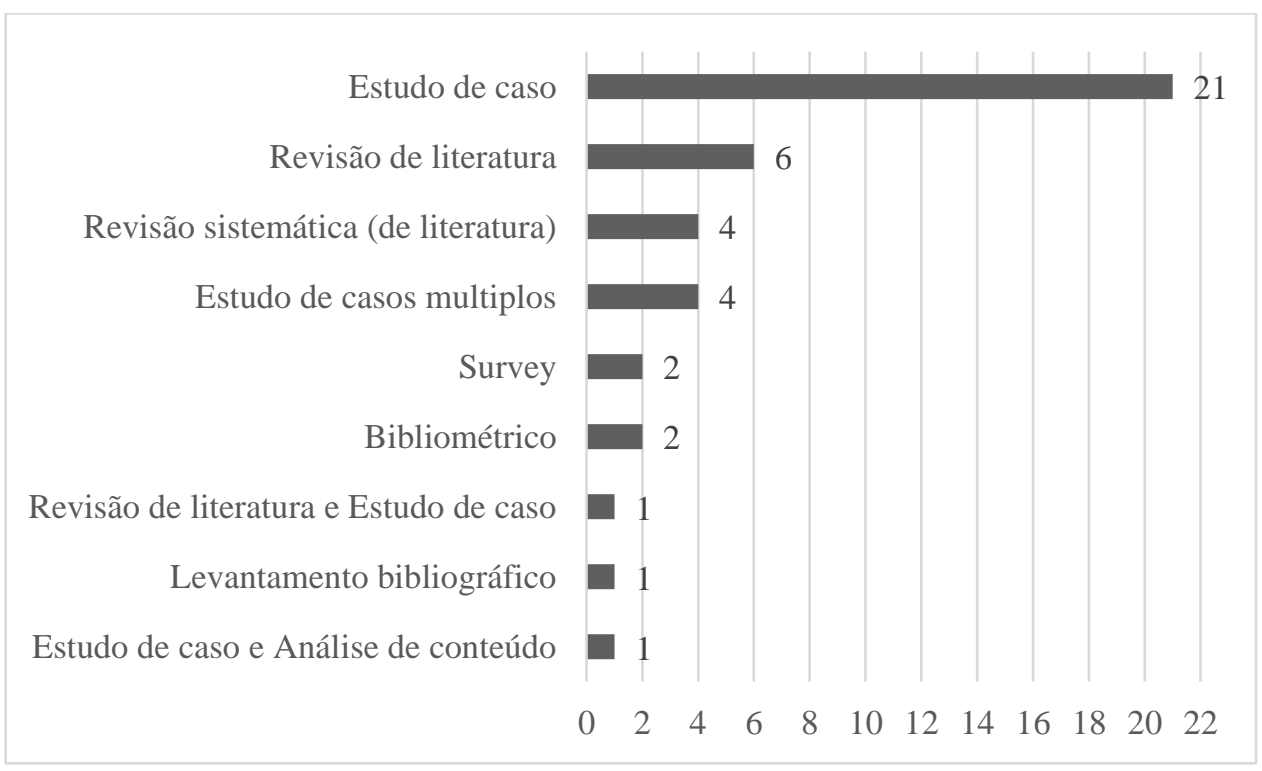

Figura 12 - Número de publicações por procedimento Fonte: Dados da pesquisa (2019) 
Ainda em relação à Figura 12, a única pesquisa bibliográfica e documental se utiliza de técnicas de bibliometria, porém, ela realiza um levantamento sobre as diferentes abordagens conceituais em sete teorias explicativas da internacionalização das empresas, a saber: Teoria do Poder de Mercado, Modelos Evolucionário; Teoria da Internalização e Teoria dos Custos de Transação, Paradigma Eclético, Visão Baseada em Recursos, Teoria Institucional e Empreendedorismo Internacional e Born Global em seis periódicos internacionais entre os anos de 1970 e 2010. Em relação às palavras-chave utilizadas nos artigos, encontra-se com maior frequência o termo
Internacionalização com 13 aparições e seguida do termo born globals com sete aparições no total. Ressalta-se que apenas cinco dos 43 artigos utilizam a palavra-chave born global ou suas variantes, mesmo o artigo tratando sobre este tema, como apresentado a seguir na Figura 13 As palavras-chave auxiliam os mecanismos de busca e indexadores a encontrar os artigos mais relevantes. Para a difusão dos trabalhos acadêmicos no tema e sua posterior citação, os termos devem ser específicos da área de estudo. No caso do levantamento feito por este trabalho, as palavras-chave não dos artigos coletados não representam as especificidades do campo de BG.

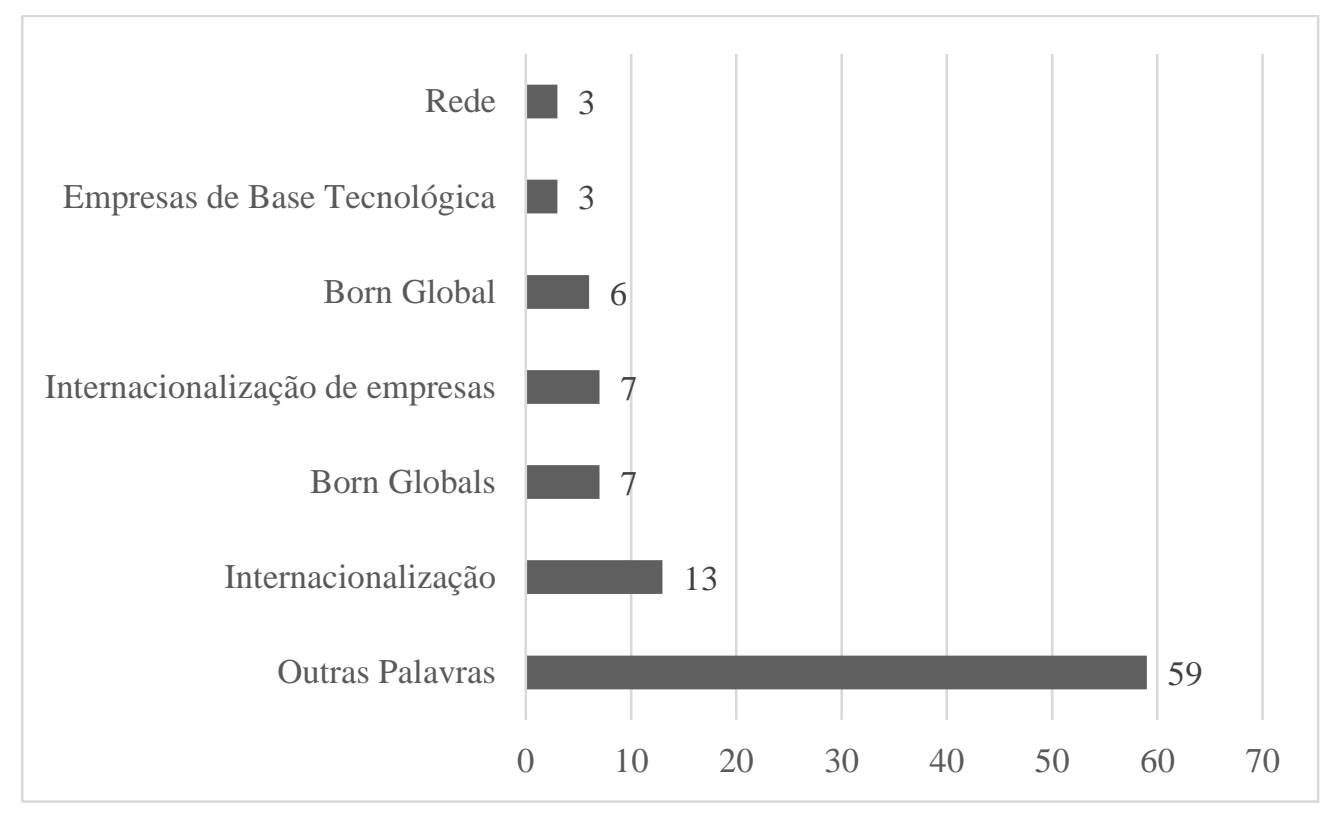

Figura 13 - Palavras-chave utilizadas nos artigos Fonte: Dados da pesquisa (2019)

A Figura 14 apresenta os idiomas das publicações. Como se era de esperar, 13 dos 43 artigos estão no idioma português, mas, destaca-se que sete deles estão no idioma inglês, idioma este que predomina nas publicações dos periódicos internacionais de renome. O aumento de publicações em língua inglesa é de grande importância para que o conhecimento gerado no Brasil sobre o tema seja difundido mais amplamente, garantindo uma maior internacionalização da produção científica do Brasil, gerando também um maior reconhecimento dos periódicos nacionais dentro da literatura de negócios internacionais. 


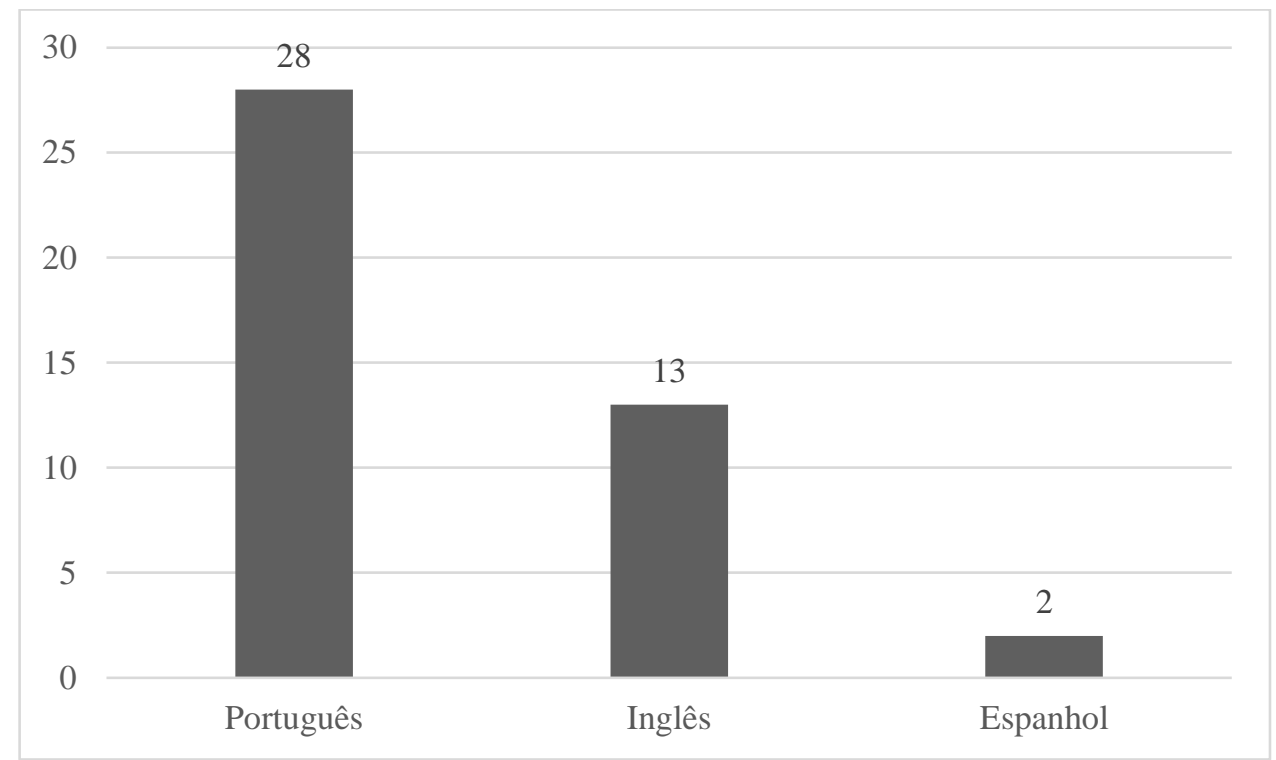

Figura 14 - Número de publicações por idioma Fonte: Dados da pesquisa (2019)

Diante dos resultados apresentados, a próxima seção trará a conclusão deste levantamento bibliométrico.

\section{CONCLUSÃO}

Pode-se concluir que o objetivo da pesquisa de investigar como está o desenvolvimento da pesquisa brasileira em BG foi alcançado. Após o levantamento bibliométrico, os resultados apresentam uma produção considerável no tema no Brasil. Foram encontrados 43 artigos, sendo um Caso de ensino, nos periódicos brasileiros de qualis $\mathrm{A} 1$ a $\mathrm{B} 3$ e nos anais do ENANPAD. Apesar de a produção ter aumentado no ano de 2017, ainda existe a necessidade maiores investigações nessa temática, principalmente estudos quantitativos, que possam explicar os fenômenos das BG por meio de uma quantidade maior de dados, trazendo mais generalizações estatísticas para contribuir com as teorias de internacionalização. Quanto ao conteúdo dos artigos, os pesquisadores tiveram um enfoque mais acentuado no processo de internacionalização das BG, com predominância de estudos de caso nos trabalhos. Além de artigos sobre a evolução do conceito, temas como empreendedorismo, inovação e estratégias de internacionalização também foram trabalhados pelos pesquisadores.

Considerando o crescente reconhecimento dessas empresas como forças de desenvolvimento tecnológico e econômico nos países, a evolução da pesquisa em BG pode trazer maiores avanços para esse tipo de empresa e, consequentemente, para o Brasil, potencializando a participação do país em redes de inovação, desenvolvimento e conhecimento (Fleury \& Fleury, 2007). Foi verificada uma demora no início dos estudos sobre BG nos periódicos brasileiros de ponta, pois embora seja um tema surgido em 1993, o primeiro artigo publicado em um periódico do Brasil foi em 2006, sendo que em periódicos internacionais o primeiro foi em 1994 (Dzikowski, 2018).

Destaca-se um significativo volume de estudos oriundos da região Sul e Sudeste do Brasil (São Paulo, Santa Catarina, Rio Grande do Sul e Rio de Janeiro). Já na abordagem adotada, percebe-se uma predominância de trabalho qualitativo e como procedimento, o estudo de caso é o mais adotado entre os artigos encontrados.

Ressalta-se que não foram realizados levantamentos sobre o tema em congressos científicos, bem como monografias, teses e dissertações sobre o tema. Para trabalhos futuros, algumas sugestões são feitas. Recomenda-se que sejam realizadas análises da produção científica em BG de outros países emergentes, para que sejam feitas comparações e traçados padrões nos estudos desse tipo de empresa e das suas características.

Além disso, análises realizadas unicamente em congressos brasileiros poderiam trazer mais 
informações e caminhos que a pesquisa em BG está traçando, uma vez que esses artigos, em grande parte, passam pelos eventos antes de serem enviados à periódicos. Outro ponto complementar a esse seria

\section{REFERÊNCIAS}

Bogaert, J., Rousseau, R., \& Van Hecke, P. (2000). Percolation as a model for informetric distributions: fragment size distribution characterised by Bradford curves. Scientometrics, 47(2), 195-206.

Borgatti, S. P., Everett, M. G., \& Freeman, L. C. (2002). Ucinet for Windows: Software for Social Network Analysis. Harvard, MA: Analytic Technologies.

Cavusgil, S. T., \& Knight, G. (2015). The born global firm: An entrepreneurial and capabilities perspective on early and rapid internationalization. Journal of International Business Studies, 46(1), 3-16.

Çakar, N. D., \& Ertürk, A. (2010). Comparing innovation capability of small and medium-sized enterprises: examining the effects of organizational culture and empowerment. Journal of Small Business Management, 48(3), 325-359.

Chetty, S., \& Campbell-Hunt, C. (2004). A strategic approach to internationalization: a traditional versus a "born-global" approach. Journal of International Marketing, 12(1), 57-81.

Chueke, G. V., \& Amatucci, M. (2015). O que é bibliometria? Uma introdução ao fórum. Internext, 10(2), 1-5.

Dib, L. A. (2008). O processo de internacionalização de pequenas e médias empresas e o fenômeno Born global: estudo do setor de software no Brasil. Universidade Federal do Rio de Janeiro.

Dib, L. A., Da Rocha, A., \& Da Silva, J. F. (2010). The internationalization process of Brazilian software firms and the born global phenomenon: Examining firm, network, and entrepreneur variables. Journal of International Entrepreneurship, 8(3), 233-253.

Dunning, J. H. (1988). The eclectic paradigm of international production: A restatement and some possible extensions. Journal of International Business Studies, 19(1), 1-31. a busca em periódicos brasileiros de outros extratos. Dessa forma, poderia ser feita uma análise comparativa entre os artigos que constam em periódicos de diferentes relevâncias acadêmicas.

Dzikowski, P. (2018). A bibliometric analysis of born global firms. Journal of Business Research, 85, 281-294.

Ferreira, A. G. C. (2010). Bibliometria na avaliação de periódicos científicos. DataGramaZero-Revista de Ciência da Informação, 11(3), 1-9.

Fleury, A., \& Fleury, M. T. (2007). Leme. Internacionalização das empresas brasileiras: em busca de uma abordagem teórica para os late movers. Internacionalização e os Países Emergentes. São Paulo: Atlas.

Gabrielsson, M., Kirpalani, V. M., Dimitratos, P., Solberg, C. A., \& Zucchella, A. (2008). Born globals: Propositions to help advance the theory. International Business Review, 17(4), 385-401.

Gil, A. C. (2002). Como elaborar projetos de pesquisa. São Paulo, 5(61), 16-17.

Guedes, V. L., \& Borschiver, S. (2005). Bibliometria: uma ferramenta estatística para a gestão da informação e do conhecimento, em sistemas de informação, de comunicação e de avaliação científica e tecnológica. CINFORMEncontro Nacional de Ciência da Informação, 6 .

Hennart, J. F. (2014). The accidental internationalists: a theory of born globals. Entrepreneurship Theory and Practice, 38(1), 117135.

Johanson, J., \& Vahlne, J. E. (1977). The internationalization process of the firm-a model of knowledge development and increasing foreign market commitments. Journal of International Business Studies, 8(1), 23-32.

Jones, M. V., \& Coviello, N. E. (2005). Internationalisation: conceptualising an entrepreneurial process of behaviour in time. Journal of International Business Studies, 36(3), 284-303. 
Keupp, M. M., \& Gassmann, O. (2009). The past and the future of international entrepreneurship: a review and suggestions for developing the field. Journal of Management, 35(3), 600-633.

Knight, G. A., \& Cavusgil, S. T. (1996). The born global firm: A challenge to traditional internationalization theory. In Cavusgil, S., \& Madsen, T. Eds. Advances in international marketing (Vol. 8). Greenwich, CT: JAI Press.

Knight, G. A., \& Cavusgil, S. T. (2004). Innovation, organizational capabilities, and the born-global firm. Journal of International Business Studies, 35(2), 124141.

Kobashi, N. Y., \& Santos, R. N. M. (2008). Arqueologia do trabalho imaterial: uma aplicação bibliométrica à análise de dissertações e teses. Encontros Bibli: Revista Eletrônica de Biblioteconomia e Ciência da Informação, 13(1), 106-115.

Souza, E., \& Lima, A. (2016). Born Globals: uma revisão da teoria e sugestões para iniciativas de pesquisa no Brasil. In XIX SEMEAD - Seminários em Administração. São Paulo: Universidade de São Paulo.

Machado Junior, C., Souza, M. T. S., Parisotto, I. R. S., \& Palmisano, A. (2016). As leis da Bibliometria em diferentes Bases de dados Científicos. Revista de Ciências da Administração, 18(44).

Madsen, T. K., \& Servais, P. (1997). The internationalization of born globals: an evolutionary process?. International Business Review, 6(6), 561583.

Neuman, W. L. (2013). Social research methods: Qualitative and quantitative approaches. Pearson education.

Oliveira, R. R., \& Sales, F. S. (2014). Estudos bibliométricos na área da administração: um estudo sobre o perfil dos pesquisadores em ambiente de inovação. In Congresso Nacional de Excelência em Gestão. Rio de Janeiro.

Oviatt, B. M., \& McDougall, P. P. (1994). Toward a theory of international new ventures. Journal of International Business Studies, 25(1), 45-64.
Oviatt, B. M., \& McDougall, P. P. (2005). Defining international entrepreneurship and modeling the speed of internationalization. Entrepreneurship Theory and Practice, 29(5), 537-554.

Rennie, M. W. (1993). Born global. The McKinsey Quarterly, (4), 45.

Rialp, A., Rialp, J., \& Knight, G. A. (2005). The phenomenon of early internationalizing firms: what do we know after a decade (1993-2003) of scientific inquiry?. International Business Review, 14(2), 147166.

Ribeiro, F. F., \& Pimentel, J. E. (2009). Empresas born globals brasileiras: a influência do perfil do empreendedor e da localização geográfica. Caderno de Administração. Revista da Faculdade de Administração da FEA. ISSN 1414-7394, 5(1).

Stocker, F., \& Abib, G. (2019). Gerenciamento de Riscos em Born globals: o caso das Cervejarias Artesanais Brasileiras. BBR. Brazilian Business Review, 16(4), 334-349.

Teixeira, M. L. M., Iwamoto, H. M., \& Medeiros, A. L. (2013). Estudos bibliométricos (?) em administração: discutindo a transposição de finalidade. Administração: Ensino e Pesquisa, 14(3), 423-452.

Van Leeuwen, T. (2006). The application of bibliometric analyses in the evaluation of social science research. Who benefits from it, and why it is still feasible. Scientometrics, 66(1), 133-154.

Verdu, F. C., \& Bulgacov, S. (2012). A internacionalização de uma pequena empresa. REBRAE, 5(2), 179-190.

Weerawardena, J., \& Mort, G. S. (2006). Investigating social entrepreneurship: A multidimensional model. Journal of World Business, 41(1), 21-35. 


\section{Sobre os autores:}

Thiago Alberto Viana de Sousa - Universidade de Fortaleza - UNIFOR, Fortaleza, CE, (Brasil). E-mail: admtviana@gmail.com Orcid id: https://orcid.org/0000-0001-9126-7381

Thomaz Novais Rocha - Fundação Getúlio Vargas - FGV, São Paulo, SP, (Brasil). E-mail: thomaznr@gmail.com Orcid id: https://orcid.org/0000-0002-9098-4079

Sergio Henrique Arruda Cavalcante Forte - Universidade de Fortaleza - UNIFOR, Fortaleza, CE, (Brasil). E-mail: sergioforte@unifor.br Orcid id: https://orcid.org/0000-0002-8406-0910

\section{THE SCIENTIFIC PRODUCTION ON BORN GLOBALS IN BRAZILIAN JOURNALS AND SCIENTIFIC CONFERENCES}

Thiago Alberto Viana de Sousa ${ }^{\Omega}$, Thomaz Novais Rocha, Sérgio Henrique Arruda Cavalcante Forte Universidade de Fortaleza - UNIFOR, Fortaleza, CE, (Brasil)

${ }^{\Omega}$ Fundação Getúlio Vargas - FGV, São Paulo, SP, (Brasil)

\section{ARTICLE DETAILS}

\section{Article history:}

Received: 13 February 2019

Accepted: 15 November 2019

Available online May: 01 th 2020

Double Blind Review System

Scientific Editor

llan Avrichir

\section{Key words}

Internationalization Process

Small business

Software

\begin{abstract}
Objective: The objective of this article was to analyze the scientific production in brazilian journals in born globals.

Method: A bibliometric analysis of the entire scientific production in Brazil up to October 2019 was carried out in journals ranked with Qualis A1 to B3 and papers published in the ANPAD Conference (ENANPAD)

Main results: On this field of research, there is a predominance of articles discussing the internationalization process of born globals and the evolution of the concept of internationalization. The largest amount of papers published on the theme are from institutions from the south and southeast of Brazil.

Relevance/originality: An analysis of the brazilian scientific production on born globals is useful for researchers in their future studies about internationalization. Theoretical/methodological contributions: This paper contributes to the theoretical evolution of the theme, presenting the development of the research in born globals in Brazil over the years.
\end{abstract}




\title{
LA PRODUCCIÓN CIENTÍFICA EN BORN GLOBALS EN LOS PERIÓDICOS Y CONGRESOS CIENTIFICOS BRASILEÑOS
}

\author{
Thiago Alberto Viana de Sousa ${ }^{\Omega}$, Thomaz Novais Rocha, Sérgio Henrique Arruda Cavalcante Forte \\ Universidade de Fortaleza - UNIFOR, Fortaleza, CE, (Brasil) \\ ${ }^{\Omega}$ Fundação Getúlio Vargas - FGV, São Paulo, SP, (Brasil)
}

\section{HISTORIA DEL ARTÍCULO}

\section{Historia del Artículo:}

Recibido: 13 de Febrero de 2019

Aceptado: 15 de Noviembre de 2019

Disponible en línea: 01 de Mayo 2020

\section{Double Blind Review System}

Editor Científico

Ilan Avrichir

Palabras-clave:

Las Born Global

Internacionalización

Empresas Internacionales

Estudio Bibliométrico

\section{RESUMEN}

Objetivo: El objetivo de este artículo es analizar la producción científica en los periódicos brasileños acerca del tema de born global.

Método: Se realizó un análisis bibliométrico de toda la producción científica hecha en Brasil, hasta octubre de 2019, es decir, calificamos los periódicos A1 a B3 y los anales de ENANPAD.

Resultados principales: acerca de del tema abordado en el artículo, se puede percibir la predominancia del proceso de internacionalización de las born globals y la evolución del concepto de internacionalización. Las instituciones del sur y sureste de Brasil, son las que contabilizan lo más grande número de publicaciones sobre el tema.

Relevancia / originalidad: Analizar la producción científica brasileña acerca de born globals es util para los investigadoras en sus futuros estudios sobre internacionalización.

Contribuciones teóricas / metodológicas: la investigación contribuyó con el desarollo teórico del objecto, además del desarollo de la investigación en born globlas en Brasil al largo de los años.

\section{Para citar este artigo:}

Sousa, T., Rocha, T., \& Forte, S. (2020). A Produção Científica em Born Globals nos Periódicos e Encontros Científicos Brasileiros. Internext, 15(2), 37-55. doi: http://dx.doi.org/10.18568/internext.v15i2.525 